\title{
DIETHYLENE GLYCOL BASED DEEP EUTECTIC SOLVENTS AND THEIR PHYSICAL PROPERTIES
}

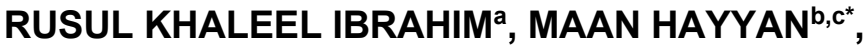 \\ MOHAMMED ABDULHAKIM ALSAADI, ${ }^{b, d}$, SHALIZA IBRAHIM ${ }^{a}$, \\ ADEEB HAYYAN ${ }^{b, d^{*}}$, MOHD ALI HASHIM ${ }^{b, e}$
}

\begin{abstract}
In this study, diethylene glycol (DEG), as a hydrogen bond donor (HBD), was mixed with three ammonium based salts, namely $\mathrm{N}, \mathrm{N}$ diethylethanolammnium chloride, tetra-n-butylammonium bromide and choline chloride, as well as two phosphonium based salts, namely benzyltriphenylphosphonium chloride and methyltriphenylphosphonium bromide, to prepare five different deep eutectic solvents (DESs) series. The DESs freezing points and functional groups were investigated. In addition, the physical properties viscosity, density, conductivity and surface tension were determined as function of temperature in the particular temperature range of $293.15-353.15 \mathrm{~K}$. It is worth mentioning that all examined DESs were stable and in liquid phase at room temperature which emphasize their promising potential to be utilized as inexpensive environment-friendlier solvents. Owing to their low recorded freezing points and viscosities, DEG based DESs can be effortlessly processed without any further heating required in diverse industrial applications.
\end{abstract}

Keywords: deep eutectic solvents; ionic liquids; diethylene glycol; physical properties; chemical processes; industrial applications.

a Department of Civil Engineering, University of Malaya, Kuala Lumpur 50603, Malaysia

b University of Malaya Centre for lonic Liquids (UMCiL), Department of Chemical Engineering, University of Malaya, Kuala Lumpur 50603, Malaysia

c Department of Chemical Engineering, Faculty of Engineering, Sohar University, P.O. Box 44, Sohar P.C. 311, Sultanate of Oman

d Nanotechnology \& Catalysis Research Centre (NANOCAT), University of Malaya, Kuala Lumpur 50603, Malaysia

e Department of Chemical Engineering, University of Malaya, Kuala Lumpur 50603, Malaysia

*Corresponding author:maan_hayyan@yahoo.com; adeeb.hayyan@yahoo.com 


\section{INTRODUCTION}

Owing to their distinctive physiochemical properties, ionic liquids (ILs) have served various purposes and gained a considerable attention in different academic and industrial fields. For instance, ILs have been used in metal extraction, in polymeric electrolyte membrane fuels cells, in Solar Cells and in biological applications such as drug delivery and activation of enzymes, as well as they have been applied as electrolytes in batteries and as reaction media for organics synthesis and biochemical reactions [1]. However, many studies have underlined the limitations of ILs, which restrain their applications on large scale in commerce, including their poor sustainability and biodegradability [2], their high toxicity to human and environment and the high required cost for their complicated synthesizing process $[3,4]$. Therefore, the emergence of deep eutectic solvents (DESs) as inexpensive solvents with easier preparation and better biodegradability [5], has enlightened the opportunities of their exploitations as appealing alternatives to maintain the useful characteristics of ILs and to overcome the challenges that hinder ILs applications $[6,7]$. Generally, the formation of DES can be easily obtained by mixing two or more of cheap and biodegradable components, namely, hydrogen bond acceptor (HBA) and hydrogen bond donor (HBD), which are connected with each other by hydrogen bond interactions [8]. DES is well characterized by its freezing point which is usually lower than that of its individual components. The main reason behind the depression of the eutectic mixture freezing point, is the delocalization of the charge occurring through hydrogen bonding between the halide anion and the HBD $[9,10]$.

Besides of having low production cost and having a good biocompatibility [11], DESs have been reported to own remarkable properties such as high viscosity, high thermal stability and low vapor pressure [12]. Therefore, many studies have been widely investigating the possibility of employing DESs in different applications [13]. For instance, DESs have shown interesting potentials in the electrochemistry technology, such as surface cleaning and metallurgy, due to their capability of donating or accepting electrons or protons to form hydrogen bonds which makes them of a great interest for dissolution of metal oxides [14]. The solubility of $\mathrm{CuO}$ in a choline chloride $(\mathrm{ChCl})$-urea $(U)$ eutectic mixture was first studied by Abbott et al. [15]. Another example, DESs have been used to remove air pollutants from gas emissions, due to their physiochemical properties which make them superior substitutes for volatile organic compounds. Yang et al. [16] explored the removal of Sulfuric dioxide $\left(\mathrm{SO}_{2}\right)$ by $(\mathrm{ChCl})$-glycerol $\mathrm{DESs}$. The results revealed the high absorption efficiency of $\mathrm{SO}_{2}$ by the eutectic mixture and which was increased by decreeing the temperature, moreover, the absorbed 
$\mathrm{SO}_{2}$ could be easily stripped out from the DES by bubbling nitrogen through the eutectic mixture [16]. In addition, the effect of different temperatures and different DES molar ratio on the solubility of carbon dioxide $\left(\mathrm{CO}_{2}\right)$ was investigated by Han and co-workers using $\mathrm{ChCl}-\mathrm{U}$ DES [17]. In like manner, Wong and co-workers explored the effect of water content on the absorption of $\mathrm{CO}_{2}$ by using $\mathrm{ChCl}-\mathrm{U}-\mathrm{H}_{2} \mathrm{O}$ [18]. These studies are considered of great concern for the development the separation and gas purification technology using DESs. Furthermore, Morison et al. [19] examined the potentials of $\mathrm{ChCl}-\mathrm{U}$ and $\mathrm{ChCl-malonic} \mathrm{acid} \mathrm{DESs} \mathrm{for} \mathrm{the} \mathrm{drug} \mathrm{solubilization,} \mathrm{Hayyan} \mathrm{et} \mathrm{al.} \mathrm{[20]} \mathrm{studied}$ the application of $\mathrm{ChCl}$-glycerol based DESs in fuel purification by extracting glycerol from palm oil-derived biodiesel, and Abbott et al. used $\mathrm{ChCl}$ Ethylene glycol (EG) as dispersant for electrodeposition of $\mathrm{Ag}$ and formation of $\mathrm{Ag} / \mathrm{SiC} / \mathrm{Al}_{2} \mathrm{O}_{3}$ nanocomposite film [21].

DESs have been reported to have a promising industrial application [22]. Therefore, in order to suggest further application and design green technologies involving DESs, many studies have extensively been attempting to cover and understand the unique and common properties of DESs followed by applying them in different chemical researches. For example, Shahbaz et al. [23, 24] had successfully predicted the density and the surface tension of different DESs, and the effect of salt to HBD molar ratio on the predicted DESs densities was investigated. Also, Yadav et al. [25] investigated the densities and the dynamic viscosities of $(\mathrm{ChCl}: \mathrm{Gl}) \mathrm{DES}$ at a temperature range of $(283.15-363.15 \mathrm{~K})$. Similarly, the main purpose of this study is to document the physical properties as function of temperature (e.g. freezing point, FTIR analysis, density, surface tension, viscosity, conductivity) of five DES systems prepared by mixing five different salts, namely $\mathrm{N}, \mathrm{N}$ diethylethanolammnium chloride, benzyltriphenylphosphonium chloride, choline chloride, methyltriphenylphosphonium bromide and tetra-n-butylammonium bromide, and diethylene glycol (DEG) as HBD. DEG is an aliphatic compound which is widely used as solvent, antifreeze, chemical feedstock, and it can be found in automotive products and wallpaper stripper [26, 27]. For our best knowledge, there are no recorded data in literature concerning the physical properties of DEG based DESs.

\section{RESULTS AND DISCUSSION}

\section{FREEZING POINT}

The selected series of DESs are in liquid form under room-temperature conditions, which facilitate their exploitations in different industrial applications. Abbott et al. [28] stated that the freezing point of DES can be partially 
measured by the melting points of the pure components parts, and it is dependent on the entropy changes, lattice energy and on the way of interaction between cation and anion components [28, 29]. The melting points of the salts used in this study, i.e., BTPC, MTPB, ChCl, DAC, and TBAB, are $603.15,507.15,575.15,409.15$, and $376.15 \mathrm{~K}$, while the freezing point of DEG is $264.15 \mathrm{k}$. Table 1 displays the freezing points of the five studied DESs and their composition and abbreviations. It is clear that all the values are in agree with the general definition of DES that characterize the DES mixture with a lower freezing point than that of its individual constituents. As can be concluded from the data, the freezing points range between 247.92- 262.39 $\mathrm{K}$, with the highest freezing point for [DAC:DEG] while the lowest freezing point for [TBAB:DEG]. All the recorded freezing points were below $323.15 \mathrm{~K}$, and as reported by Zhang et al. [30], DESs with freezing points lower than $323.15 \mathrm{~K}$ are more attractive to be employed as cheap and safe ambient temperature solvents in many different fields.

Table 1. Composition, abbreviations and freezing point for the studied DESs.

\begin{tabular}{|c|c|c|c|c|c|c|}
\hline Salt* & $\begin{array}{l}\text { Salt } \\
\text { Molar } \\
\text { ratio }\end{array}$ & HBD & $\begin{array}{l}\text { HBD } \\
\text { Molar } \\
\text { ratio }\end{array}$ & $\begin{array}{l}\text { DES } \\
\text { Abbreviation }\end{array}$ & $\begin{array}{l}\text { DES } \\
\text { molecular } \\
\text { weight }\end{array}$ & $\begin{array}{l}\text { Freezing } \\
\text { point. } \\
\text { (Tf } / K \text { ) }\end{array}$ \\
\hline $\mathrm{ChCl}$ & 1 & \multirow{5}{*}{$\mathrm{DEG}^{* *}$} & 2 & [ChCl:DEG] & 117.288 & 260.52 \\
\hline DAC & 1 & & 3 & [DAC:DEG] & 118.002 & 262.39 \\
\hline TBAB & 1 & & 2 & [TBAB:DEG] & 178.202 & 247.92 \\
\hline BTPC & 1 & & 7 & [BTPC:DEG] & 141.463 & 248.52 \\
\hline MTPB & 1 & & 4 & [MTPB:DEG] & 156.340 & 248.39 \\
\hline
\end{tabular}

a Freezing point value represents the average point between the first crystal appearance and the last liquid drop disappearance. All freezing point data are reported at pressure of $0.1 \mathrm{MPa}$. ${ }^{*} \mathrm{ChCl}$ : choline chloride, DAC: N,N-diethylethanolammonium chloride, TBAB: tetra-n-butylammonium bromide, BTPC: benzyltriphenylphosphonium chloride, MTPB: methyltriphenylphosphonium bromide. ${ }^{* *}$ DEG: diethylene glycol.

\section{FTIR}

The result of FTIR analysis is shown in Figure 1 indicates that the pure constituents of DESs (salt-HBD) have obvious effects on the structure of the DESs. The effect of DEG as HBD can be noticed in all DESs spectrums at peaks between $3500-3200 \mathrm{~cm}^{-1}$, representing the O-H stretching bond [31-34]. Moreover, due to the utilization of DEG as HBD in the current DESs synthesizing process, the spectral peaks of the examined DES systems are virtually alike. 
On the other hand, the effect of salts can be inferred from the existence of the $\mathrm{P}-\mathrm{H}$ bonds in the structure of phosphonium based DESs, which could be overlapped with $\mathrm{C}-\mathrm{H}$ bands at the region between $3000-2800 \mathrm{~cm}^{-1}[31,33,34]$. In addition, the effect of salts on ammonium based DESs assimilated in the presence of ammonium structures between $3200-2400 \mathrm{~cm}^{-1}$, mainly $\mathrm{N}-\mathrm{H}$ stretch at $2870 \mathrm{~cm}^{-1}$ [33-36]. For all examined DESs, the intense absorption bands at $\left(800-700 \mathrm{~cm}^{-1}\right)$ and $\left(700-600 \mathrm{~cm}^{-1}\right)$ were assigned to aliphatic organohalogen compounds with stretching bonds $(\mathrm{C}-\mathrm{Cl})$ and $(\mathrm{C}-\mathrm{Br})$ respectively [32]. Furthermore, the strong bonds ranging from $\left(1200-1050 \mathrm{~cm}^{-1}\right),\left(1600-1800 \mathrm{~cm}^{-1}\right)$, and $\left(1400-1340 \mathrm{~cm}^{-1}\right)$ are assigned to $\mathrm{C}-\mathrm{O}, \mathrm{C}=\mathrm{O}$ and $\mathrm{N}-\mathrm{O}$ correspondingly. The stretch PO4-3 at (1100-1000 $\left.\mathrm{cm}^{-1}\right)$ [32, 34] was strong and broad in [MTPB:DEG] and [BTPC:DEG] while peaks at $\left(1310-1230 \mathrm{~cm}^{-1}\right)[32,34]$ representing $\mathrm{C}-\mathrm{N}$ stretch, were explicit in [ChCl:DEG], [DAC:DEG], and [TBAB:DEG].

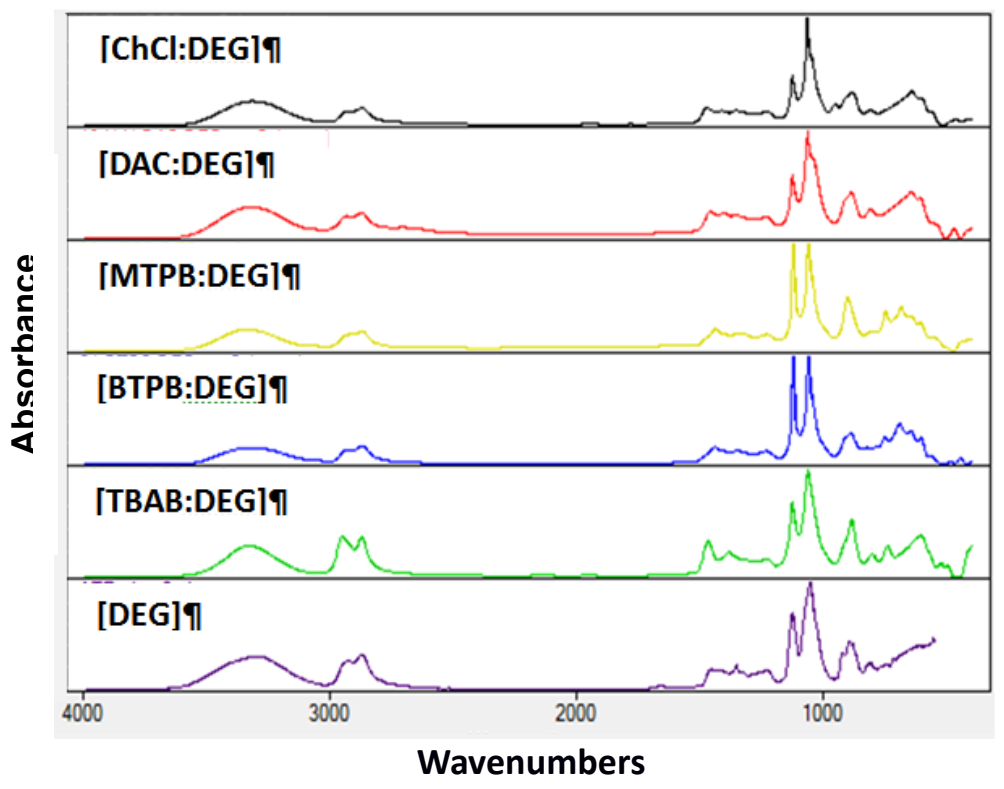

\section{Density}

The density values of the five selected DESs as function of temperature are illustrated in Figure 2. At room temperature, [MTPB:DEG] attained the highest density of $1.209 \mathrm{~g} . \mathrm{cm}^{-3}$, whereas [TBAB:DEG] attained the lowest density

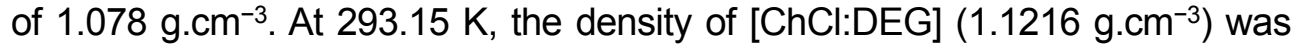
found to be similar to that of [ChCl: ethylene glycol] $\left(1.12{\mathrm{~g} . \mathrm{cm}^{-3}}^{-3}[37,38]\right.$,and 
lower than that of [ChCl:urea] $\left(1.25 \mathrm{~g}_{\mathrm{cm}}{ }^{-3}\right)$ [39-41]. Additionally, [MTPB:DEG] had a density value of $1.209{\mathrm{~g} . \mathrm{cm}^{-3}}^{-3}$ which was lower than the reported density for [MTPB:glycerol] (1.30 g.cm-3) [42], and slightly higher than that reported for [MTPB: triethylene glycol] $\left(1.19 \mathrm{~g} . \mathrm{cm}^{-3}\right)$ [43]. For further comparison purposes, Table 3 is arranged to compare the densities of the studied DESs with those of some reported ILs in literature.

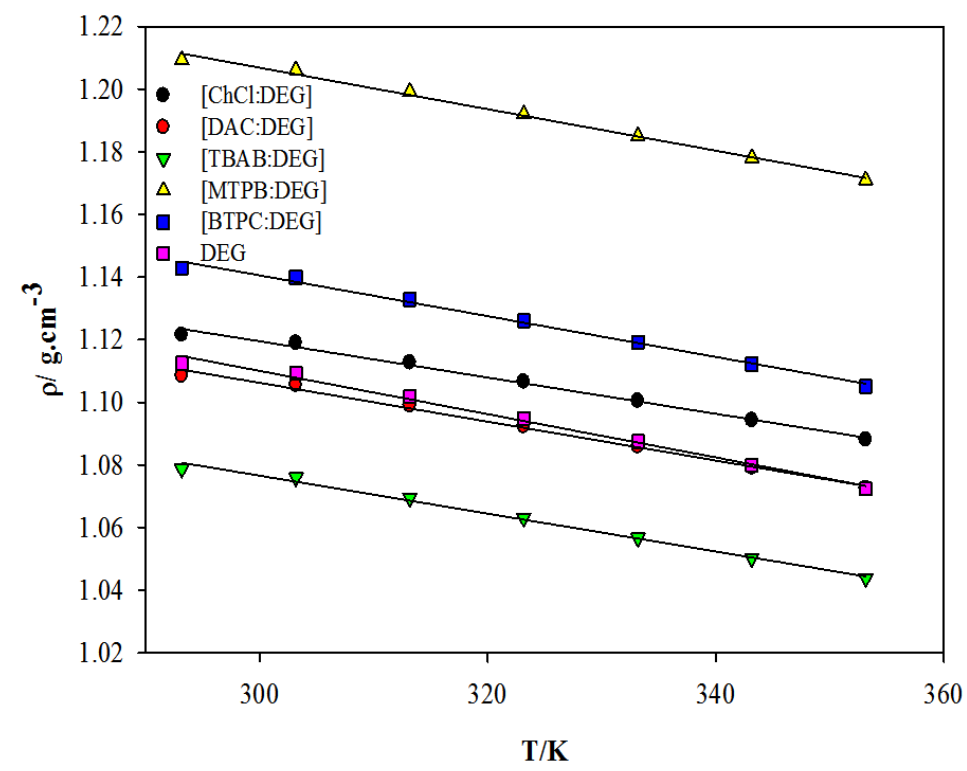

Figure 2. Densities for DEG based DESs as a function of temperature.

The calculated densities using the simple mixing rule (Eq 1) [44] were found to be incompatible with the recorded experimental densities and that indicates the interaction of both components molecules and confirms the hydrogen bonding formation which reduces the molecular distance between the salt and HBD.

$$
\frac{1}{\rho_{m}}=\sum_{i} \frac{x_{i}}{\rho_{i}}
$$

where $\rho_{m}$ is the density of DES mixture $\left(\mathrm{gm.cm}^{-3}\right), x_{i}$ is mass fraction of component $\mathrm{i}$, and $\rho_{i}$ is the density of component $\mathrm{i}\left(\mathrm{gm} . \mathrm{cm}^{-3}\right)$.

Moreover, the densities of the examined DESs series decreased with the increase of temperature due to the effects of the increased internal energy on the mobility of DES molecule resulting in increasing the thermal expansion of DES volume [45]. 


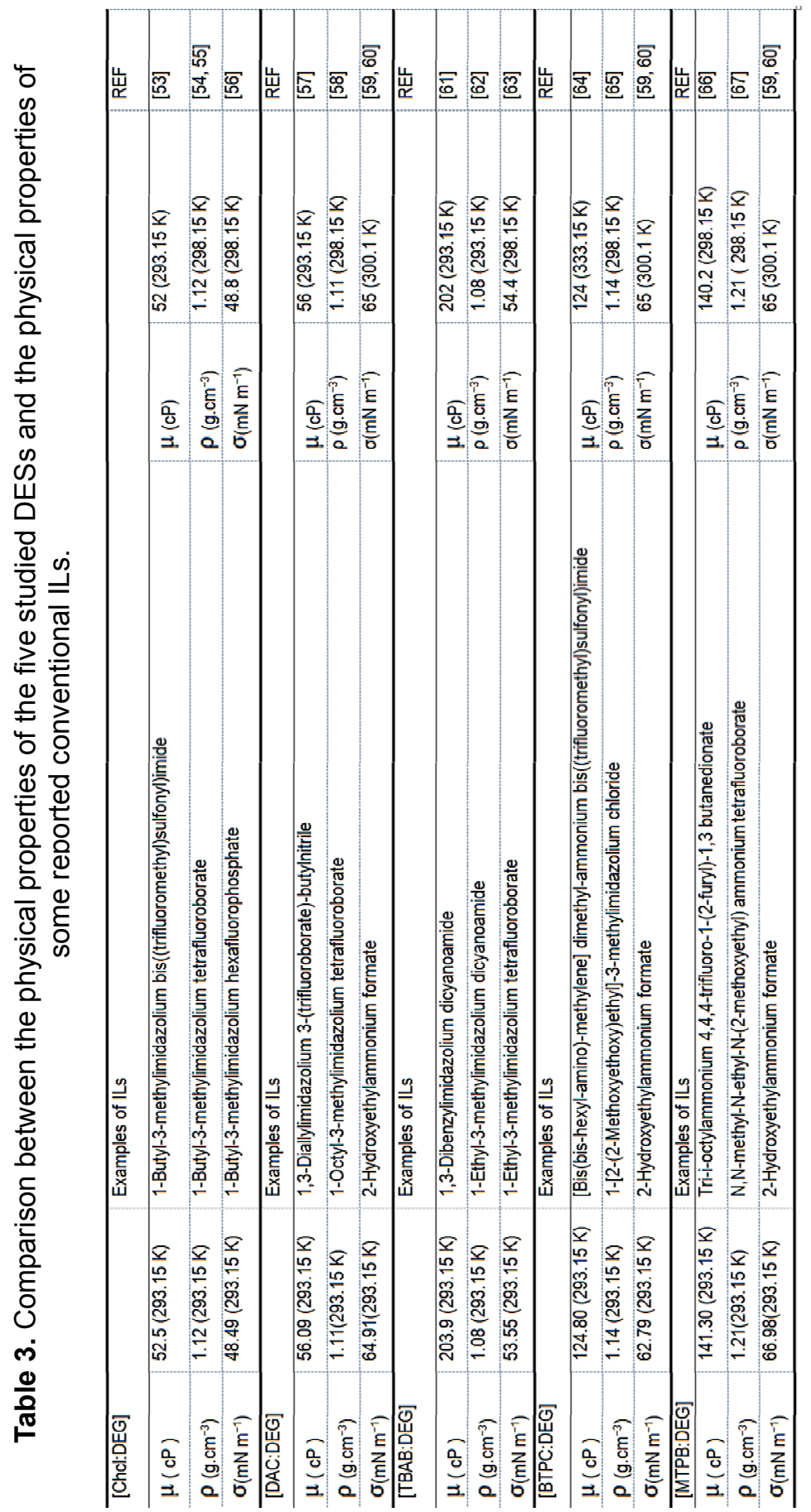


For all examined DESs, the density-temperature relationship was fitted linearly using Eq 2 with regression values $R^{2}$ of 0.99 .

$$
\rho=a+b \mathrm{~T}
$$

where $\rho$ is the density, T is temperature in Kelvin, and a and b are constants and their values are listed in Table 4.

Table 4. Density- temperature model parameters.

\begin{tabular}{|c|c|c|c|}
\hline DES & $\boldsymbol{a}$ & $\boldsymbol{b}$ & $\mathbf{R}^{\mathbf{2}}$ \\
\hline [ChCl:DEG] & 1.2932 & -0.0006 & 0.99 \\
\hline [DAC:DEG] & 1.2922 & -0.0006 & 0.99 \\
\hline [TBAB:DEG] & 1.2581 & -0.0006 & 0.99 \\
\hline [BTPC:DEG] & 1.3358 & -0.0007 & 0.99 \\
\hline [MTPB:DEG] & 1.4055 & -0.0007 & 0.99 \\
\hline
\end{tabular}

\section{Viscosity and conductivity}

The values of viscosity and conductivity are the prominent attributes of DESs to be utilized as significant candidates as an electrolyte in electrochemical applications such as batteries, electroplating, and electrolysis. Figure 3 and Figure 4 elucidate the effect of temperature on the viscosity and the electrical conductivity of the studied DESs, respectively. For all selected DESs, the noted values of viscosity and conductivity were determined at temperature range of (293.15-353.15 K), and both of these physical properties for DESs were higher than those for DEG. At room temperature, the deliberated DESs series had the following viscosity sequence: [TBAB:DEG] > [MTPB:DEG] > [BTPC:DEG] > [DAC:DEG] > [ChCl:DEG]; while their conductivity order was as following: [ChCl:DEG] > [DAC:DEG] > [MTPB:DEG] > [BTPC:DEG] > [TBAB:DEG]. It is noticeable that DES with the highest viscosity attained the lowest conductivity value due to the extreme high consistency of DES mixture that constrained the transmission of the electrical current through the mixture. Another significant factor that has a perceptible impact on the viscosity and conductivity values is the ratio of salt in the DES mixture. Table 5 depicts that although [MTPB:DEG] has a higher viscosity than that of [BTPC:DEG], it recorded a 
higher electrical transmission ability due to its high salt ratio content; moreover, it can be concluded from Table 5 that DES viscosity data is relatively proportional to the ratio of salt in DESs. It is noteworthy, that the temperature has an adverse influence on the viscosity because of the energetic motion gained by DESs molecules when the temperature increases, resulting in reducing the strength of intermolecular forces, decreasing the mixture viscosity and consequently increasing its conductivity.

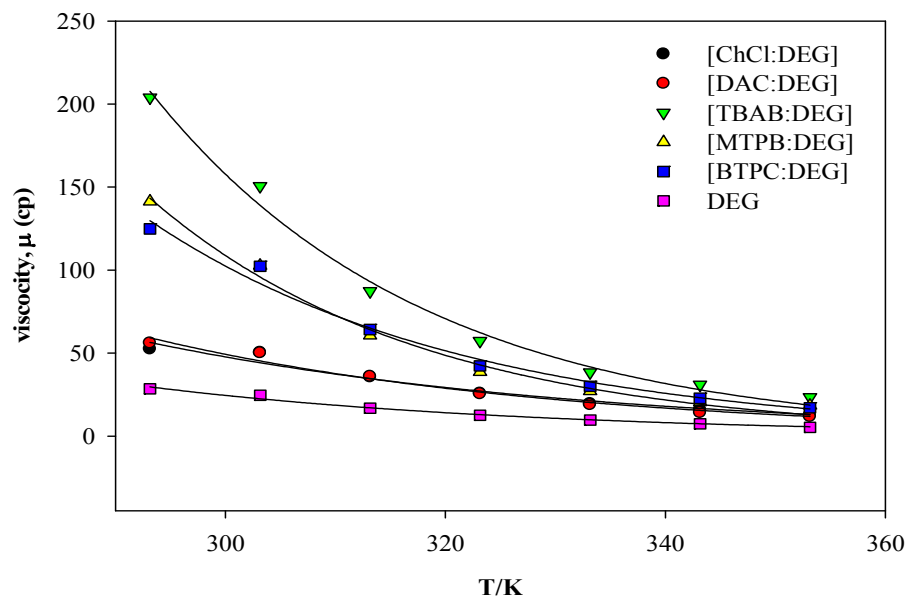

Figure 3. Viscosities for DEG based DESs a function of temperature

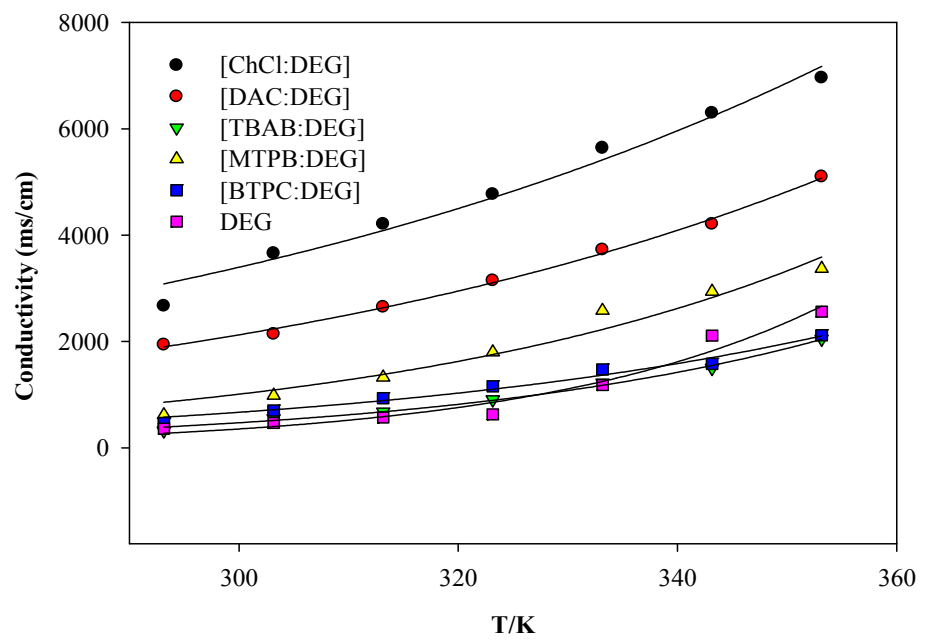

Figure 4. Conductivities for DEG based DESs as a function of temperature 
Comparing the current considered DES systems with previous works, reveals that [ChCl:DEG] had a viscosity value of (52.49 cP at $293.15 \mathrm{~K})$ higher than that of [ChCl: ethylene glycol] $(37.0 \mathrm{cP}$ at $298.15 \mathrm{~K})$ [46], lower than that of [TBAC:EG] (>200 cP at $293.15 \mathrm{~K}$ ) [45] and extremely lower than that of [Chcl: zinc chloride] ( $85000 \mathrm{cP}$ at $298.15 \mathrm{~K}$ ) [47]. Also, the viscosity of [MTPB:glycerol] was reported to be very high ( $2775.9 \mathrm{cP}$ ) at $298.15 \mathrm{~K}$ [48], while the viscosity of [MTPB:DEG] in this study was found to be comparatively low $(141.3 \mathrm{cP})$ at $293.15 \mathrm{~K}$. All the recorded viscosities of the concerned DESs at $353.15 \mathrm{~K}$ were much lower than the lowest viscosities values reported for triethylene glycol (TEG) based DESs [35].

Table 5. Salt ratio effect on the viscosity and conductivity (At 293.15 K).

\begin{tabular}{|c|c|c|c|}
\hline DES & Salt ratio & $\boldsymbol{\mu}(\mathbf{c P})$ & $\mathbf{S}(\boldsymbol{\mu s} / \mathbf{c m})$ \\
\hline [ChCl:DEG] & 30.49 & 52.49 & 2670 \\
\hline [DAC:DEG] & 32.55 & 56.09 & 1940 \\
\hline [TBAB:DEG] & 60.3 & 203.9 & 325 \\
\hline [BTPC:DEG] & 34.36 & 124.8 & 466 \\
\hline [MTPB:DEG] & 45.7 & 141.3 & 618 \\
\hline
\end{tabular}

Additionally, Table 3 presents a simple comparison between the viscosities of the studied DESs with some reported ILs. On the other hand, the conductivity of [DAC:DEG] $\left(2040 \mu \mathrm{S} . \mathrm{cm}^{-1}\right)$ at $298.15 \mathrm{~K}$ was found to be higher than that of [DAC: malonic acid] $\left(1130 \mu \mathrm{S} . \mathrm{cm}^{-1}\right)$ and much lower than that of [DAC: zinc nitrate] $\left(7050 \mu \mathrm{S} . \mathrm{cm}^{-1}\right)$ [49]. The conductivity of [ChCl:DEG] at 293.15 was found to be $\left(2670 \mu \mathrm{S} . \mathrm{cm}^{-1}\right)$ which is higher than that of [ChCl: 1,4-butanediol] $\left(1654 \mu{\mathrm{S} . \mathrm{cm}^{-1}}^{-1}\right.$ [50] and that of $[\mathrm{ChCl}$ : triethanolamine] $\left(650 \mu \mathrm{S} . \mathrm{cm}^{-1}\right)$ [49]. It is worth mentioning that in this study $\mathrm{ChCl}$ salt based DES had attained the lowest viscosities and the highest conductivities among all DESs and that was similar to the reported case of $\mathrm{ChCl}$ salt based DES with glycerol (GLY) as HBD [48].

The trend of viscosity-temperature can be expressed with a regression value (R2) higher than 0.97 for all DESs by the following Arrhenius-like equation, Eq 3 [51]:

$$
\mu=\mu_{\circ} e^{\left[\frac{E \mu}{R T}\right]}
$$

where $\mu$ is the viscosity, $\mu_{0}$ is a pre-exponential factor, $\mathrm{E} \mu$ is the viscosity activation energy, $\mathrm{R}$ is them gas constant and $\mathrm{T}$ is temperature in $\mathrm{K}$.

The model parameter values are listed in Table 6. 
Table 6. Viscosity- temperature model parameters.

\begin{tabular}{|c|c|c|c|}
\hline $\mathbf{D E S}$ & $\boldsymbol{\mu}_{\circ}$ & $\left.\mathbf{( E \mu} \mathbf{R}^{-1}\right)$ & $\mathbf{R}^{\mathbf{2}}$ \\
\hline [ChCl:DEG] & $7 \times 10^{-3}$ & 2654.02 & 0.97 \\
\hline [DAC:DEG] & $3 \times 10^{-3}$ & 2908.94 & 0.98 \\
\hline [TBAB:DEG] & $4 \times 10^{-4}$ & 3892.81 & 0.99 \\
\hline [BTPC:DEG] & $6 \times 10^{-4}$ & 3599.62 & 0.99 \\
\hline [MTPB:DEG] & $3 \times 10^{-4}$ & 3784.48 & 0.98 \\
\hline
\end{tabular}

The trend of conductivity-temperature is similar to that of viscositytemperature but in the opposite direction and it can also be fitted using the following Arrhenius model, Eq 4 [52]:

$$
S=S_{\circ} e^{\left[\frac{-E_{S}}{R T}\right]}
$$

where $S$ is the conductivity in $(\mu \mathrm{s} / \mathrm{cm}), S \circ$ is pre-exponential factor, $E_{S}$ is the activation energy of electrical conduction, $\mathrm{R}$ is the gas constant, and $\mathrm{T}$ is the temperature in $\mathrm{K}$. The model parameter and the regression coefficient values for all five DESs are arranged in Table 7.

Table 7. Conductivity- temperature model parameters.

\begin{tabular}{|c|c|c|c|}
\hline $\mathbf{D E S}$ & $\boldsymbol{S}_{\circ}$ & $\left.\mathbf{( E}_{\mathbf{s}} \mathbf{R}^{-\mathbf{1}}\right)$ & $\mathbf{R}^{\mathbf{2}}$ \\
\hline [ChCl:DEG] & $6 \times 10^{5}$ & -1584.26 & 0.98 \\
\hline [DAC:DEG] & $6 \times 10^{5}$ & -1697.13 & 0.99 \\
\hline [TBAB:DEG] & $1 \times 10^{7}$ & -3010.37 & 0.99 \\
\hline [BTPC:DEG] & $2 \times 10^{6}$ & -2461.27 & 0.98 \\
\hline [MTPB:DEG] & $2 \times 10^{7}$ & -2960.37 & 0.98 \\
\hline
\end{tabular}

\section{Surface tension}

The surface tension is one of the important properties that affects the reactivity of DESs and it is one of the crucial liquid characterization that is required in many industries. Figure 5, represents the surface tension of the studied DESs as function of temperature. 


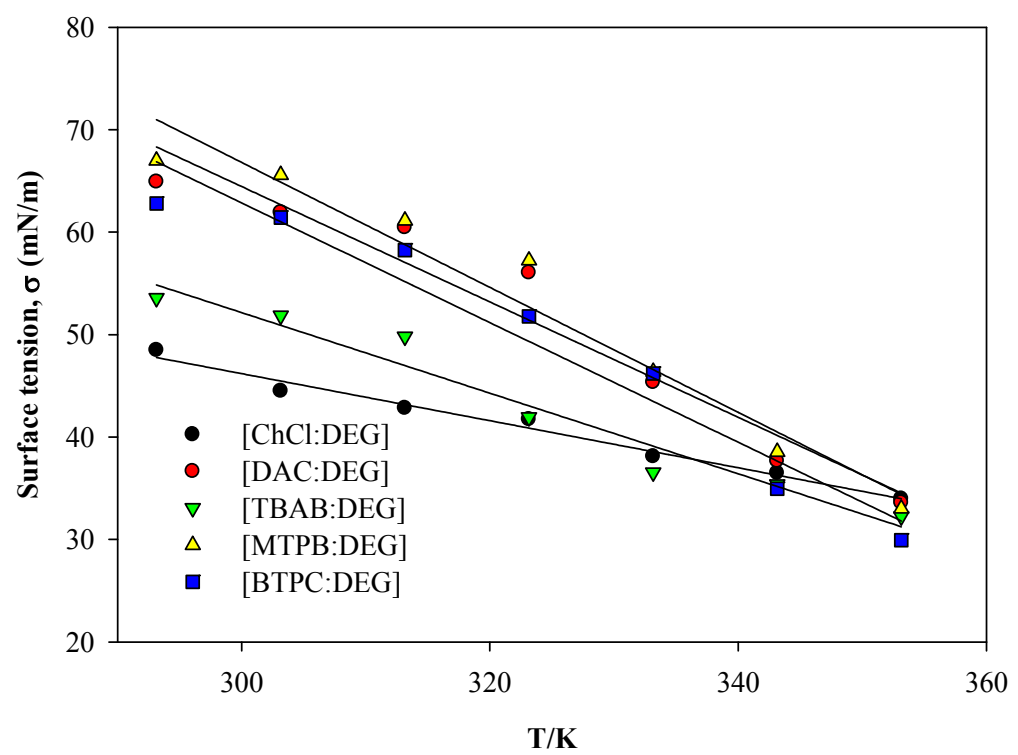

Figure 5. Surface tension for DEG based DESs as a function of temperature

At $293.15 \mathrm{~K}$, the highest surface tension value was $66.98 \mathrm{mN} \mathrm{m}^{-1}$ for [MTPB:DEG], while the lowest surface tension value was $48.49 \mathrm{mN} \mathrm{m}^{-1}$ for [ChCl:DEG]. At $353.15 \mathrm{~K}$, the surface tension of [MTPB:DEG], [ChCl:DEG] and [DAC:DEG] were almost the same with a value of $33.0 \mathrm{mN} \mathrm{m}^{-1}$. Comparatively, at $313.15 \mathrm{~K}$, the surface tension of [ChCl:DEG] $\left(42.82 \mathrm{mN} \mathrm{m}^{-1}\right)$ was higher than that of [ChCl: 2,2,2-trifluoroacetamide] $\left(35.9 \mathrm{mN} \mathrm{m}^{-1}\right)$ [40]. Meanwhile, at $293.15 \mathrm{~K}$, [ChCl:DEG] had a surface tension value (48.49 $\left.\mathrm{mN} \mathrm{m}^{-1}\right)$ higher than that of [ChCl: 1,4 -butanediol] $\left(47.6 \mathrm{mN} \mathrm{m}^{-1}\right)$ and lower than that of [ChCl:Glycerol] $\left(50.8 \mathrm{mN} \mathrm{m}^{-1}\right)$ [30]. More comparison examples between the studied DESs and ILs are listed in Table 3.

As expected, the trend of the surface tension-temperature is similar to that of viscosity-temperature, since both of the properties are highly dependent on the strength of the molecular interaction that rules the formation of DES mixture [30]. As can be simplified from Figure 5, when the temperature increases, the surface tension of DES decreases because of the reduced effects of the cohesive forces between the surface molecules which is resulted from the vibrant motion of molecules due to the thermal expansion [45]. The surface tension-temperature relationship was linearly fitted according to Eq 5: 


$$
\sigma=a+b \mathrm{~T}
$$

where $\sigma$ is the surface tension, $\mathrm{T}$ is the temperature in $\mathrm{K}$, and $a$ and $b$ are constants. The model parameters along with the regression coefficient values $\left(R^{2}\right)$ are shown in Table 8.

Table 8. Surface tension-temperature model parameters.

\begin{tabular}{|c|c|c|c|}
\hline DES & $\mathbf{a}$ & $\mathbf{b}$ & $\mathbf{R 2}$ \\
\hline [ChCl:DEG] & 115.0892 & -0.2297 & 0.98 \\
\hline [DAC:DEG] & 233.3722 & -0.5631 & 0.94 \\
\hline [TBAB:DEG] & 170.1202 & -0.3932 & 0.95 \\
\hline [BTPC:DEG] & 238.0510 & -0.5840 & 0.95 \\
\hline [MTPB:DEG] & 249.7380 & -0.6098 & 0.95 \\
\hline
\end{tabular}

\section{CONCLUSIONS}

The physical properties of the five DES systems were obtained at a temperature range of 293.15- $353.15 \mathrm{~K}$. At $293.15 \mathrm{~K}$, [TBAB: DEG] attained the highest viscosity with a value of $203.9 \mathrm{cP}$ and the lowest conductivity with a value of $325 \mu \mathrm{s} . \mathrm{cm}^{-1}$. Both surface tension and density data decreased with the increase of temperature and their temperature trends were fitted linearly. By contrast, the temperature trends for the conductivity and viscosity were exponential growth and exponential decay, respectively, and both of the trends were successfully fitted to Arhenius-like model. The freezing points of all considered DESs series were below $323.15 \mathrm{~K}$, and compatible with the general definition of DES. The FTIR analysis revealed the existence of $\mathrm{P}-\mathrm{H}$ bonds in the structure of phosphonium salts based DESs, and the presence of $\mathrm{N}-\mathrm{H}$ in the structure of ammonium based salts DESs. The physical properties of DEG based DESs were found to be similar to those of some reported ILs. The variation in the temperature, and/or the DESs individual components, and/or the ratio of salt to HBD are of a considerable concern to obtain a eutectic mixture with adaptable physical characterizations to a specific type of application, which consequently contributes in widening the horizon of DESs employment as ILs alternatives. 


\section{EXPERIMENTAL}

$\mathrm{N}, \mathrm{N}$-diethylethanolammonium chloride (DAC), tetra-n-butylammonium bromide (TBAB), methyltriphenylphosphonium bromide (MTPB), benzyltriphenylphosphonium chloride (BTPC), and diethylene glycol (DEG) were all supplied by Merck, while choline chloride $(\mathrm{ChCl})$ was supplied by sigma Aldrich. All chemicals were supplied with purity ( $\geq 98.0 \%)$ except $\mathrm{ChCl}$ and TBAB their purity was $(\geq 99.0 \%)$. The chemicals were dried in a vacuum oven for $3 \mathrm{~h}$ before conducting any experiments to prevent the adverse effects of moisture content on the physical properties measurements. Figure 6 displays the chemical structure and molecular formula of the chemicals used in this work.

The optimum DES composition ratio, at which DES is homogeneous and stable, was determined by carrying out an incipient screening where different ratios of salt to HBD were stirred at $180 \mathrm{rpm}$ and $343.15 \mathrm{~K}$ for 120 min. The five selected DESs along with their relevant optimum ratios are listed in Table 1 were prepared at atmospheric pressure in moisture controlled environment followed by measurements of their physical properties as function of temperature in the range $293.15-353.15 \mathrm{~K}$.
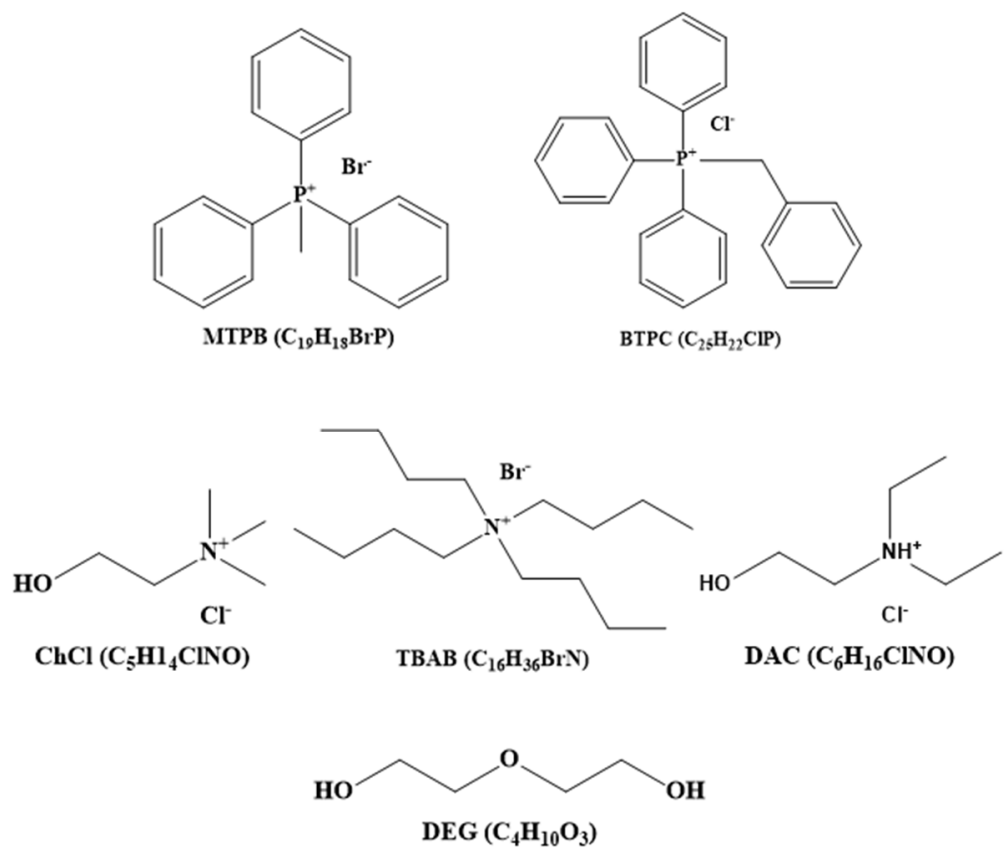

Figure 6. The chemical structure and molecular formula of DESs components 
The functional groups were identified using spectrum 400 FT-IR spectrometer. Freezing points of the five selected DESs were measured using differential scanning calorimetry (DSC) METTLER TOLEDO, Figures $6 S$ to 10S. A density meter (DM 40) METTLER TOLEDO, a Brookfield R/S Rheometer and an automated tensiometer Krüs K10ST classification B with Du Noüy ring method were utilized to determine densities, viscosities and surface tensions correspondingly. The conductivity of selected DESs was measured using Eutech Cyberscan Con 11 hand-held meter and the variation in the temperature range was controlled using an external water circulator (Techne-Tempette TE-8A). The standard uncertainties in measurements of each studied physical property are listed in Table 9.

Table 9. Standard uncertainties of measurements.

\begin{tabular}{|c|c|}
\hline Measurements & Estimated uncertainties \\
\hline Density $\left(\mathrm{g} \cdot \mathrm{cm}^{-3}\right)$ & \pm 0.0001 \\
\hline Viscosity (cP) & (3-5) \% \\
\hline Surface tension $\left(\mathrm{mN} \mathrm{m}^{-1}\right)$ & \pm 0.1 \\
\hline Conductivity ( $\mu \mathrm{s} / \mathrm{cm})$ & \pm 18 \\
\hline Freezing point (K) & \pm 0.01 \\
\hline
\end{tabular}

\section{ACKNOWLEDGMENTS}

The author would like to acknowledge financial support from the UMRP grant RP019C-13AET for research assistantship (RKI) and materials. University of Malaya HIR-MOHE (D000003-16001) is also acknowledged for use of analytical instruments.

\section{REFERENCES}

1. Patel, D.D. and J.M. Lee, The Chemical Record, 2012, 12, 329.

2. Paiva, A., R. Craveiro, I. Aroso, M. Martins, R.L. Reis, and A.R.C. Duarte, ACS Sustainable Chemistry \& Engineering, 2014, 2, 1063.

3. Hou, Y., Y. Gu, S. Zhang, F. Yang, H. Ding, and Y. Shan, Journal of Molecular Liquids, 2008, 143, 154. 
4. Dai, Y., J. van Spronsen, G.-J. Witkamp, R. Verpoorte, and Y.H. Choi, Analytica chimica acta, 2013, 766, 61.

5. Lee, Y.R. and K.H. Row, Journal of Industrial and Engineering Chemistry, 2016.

6. Durand, E., J. Lecomte, and P. Villeneuve, European Journal of Lipid Science and Technology, 2013, 115, 379.

7. Tang, B. and K.H. Row, Monatshefte für Chemie-Chemical Monthly, 2013, 144, 1427.

8. Pena-Pereira, F. and J. Namieśnik, ChemSusChem, 2014, 7, 1784.

9. Carriazo, D., M.C. Serrano, M.C. Gutiérrez, M.L. Ferrer, and F. del Monte, Chemical Society Reviews, 2012, 41, 4996.

10. Hayyan, M., M.A. Hashim, M.A. Al-Saadi, A. Hayyan, I.M. AINashef, and M.E. Mirghani, Chemosphere, 2013, 93, 455.

11. Hayyan, M., M.A. Hashim, A. Hayyan, M.A. Al-Saadi, I.M. AINashef, M.E. Mirghani, and O.K. Saheed, Chemosphere, 2013, 90, 2193.

12. Maugeri, Z. and P.D. de María, Green Chem, 2011, 13, 82.

13. Hayyan, M., C.Y. Looi, A. Hayyan, W.F. Wong, and M.A. Hashim, PloS one, 2015, 10, e0117934.

14. Abbott, A.P., G. Frisch, J. Hartley, and K.S. Ryder, Green Chemistry, 2011, 13, 471.

15. Abbott, A.P., D. Boothby, G. Capper, D.L. Davies, and R.K. Rasheed, Journal of the American Chemical Society, 2004, 126, 9142.

16. Yang, D., M. Hou, H. Ning, J. Zhang, J. Ma, G. Yang, and B. Han, Green Chemistry, 2013, 15, 2261.

17. Li, X., M. Hou, B. Han, X. Wang, and L. Zou, Journal of Chemical \& Engineering Data, 2008, 53, 548.

18. Su, W.C., D.S.H. Wong, and M.H. Li, Journal of Chemical \& Engineering Data, 2009, 54, 1951.

19. Morrison, H.G., C.C. Sun, and S. Neervannan, International journal of pharmaceutics, 2009, 378, 136.

20. Hayyan, M., F.S. Mjalli, M.A. Hashim, and I.M. AINashef, Fuel Processing Technology, 2010, 91, 116.

21. Abbott, A.P., G. Capper, K.J. McKenzie, and K.S. Ryder, Journal of Electroanalytical Chemistry, 2007, 599, 288.

22. Guo, Z. and X. Lin, Journal of Electroanalytical Chemistry, 2005, 576, 95.

23. Shahbaz, K., F. Mjalli, M. Hashim, and I. AINashef, Thermochimica acta, 2011, 515, 67.

24. Shahbaz, K., F. Mjalli, M. Hashim, and I. AlNashef, Fluid phase equilibria, 2012, 319, 48.

25. Yadav, A., S. Trivedi, R. Rai, and S. Pandey, Fluid Phase Equilibria, 2014, 367, 135.

26. Manfra, L., A. Tornambè, F. Savorelli, A. Rotini, S. Canepa, M. Mannozzi, and A. Cicero, Journal of hazardous materials, 2015, 284, 130.

27. Marraffa J.M., Diethylene Glycol, in: Wexler P., eds., Encyclopedia of Toxicology (Third Edition), Academic Press, Oxford, 2014, 140. 
28. Abbott A.P., Boothby D., Capper G., Davies D.L., Rasheed R.K., J. Am. Chemical Society, 2004, 126, 9142.

29. Liu, Y.-T., Y.-A. Chen, and Y.-J. Xing, Chinese Chemical Letters, 2014, 25, 104.

30. Zhang, Q., K.D.O. Vigier, S. Royer, and F. Jérôme, Chemical Society Reviews, 2012, 41, 7108.

31. Stuart, B., Infrared spectroscopy. 2005: Wiley Online Library.

32. Coates, J., Encyclopedia of analytical chemistry, 2000.

33. Roeges, N.P., A guide to the complete interpretation of infrared spectra of organic structures. 1994: Wiley.

34. Smith, B., Boca Raton, 1999.

35. Hayyan, M., T. Aissaoui, M.A. Hashim, M.A. AlSaadi, and A. Hayyan, Journal of the Taiwan Institute of Chemical Engineers, 2015, 50, 24.

36. Luo, J., O. Conrad, and I.F. Vankelecom, Journal of Materials Chemistry, 2012, 22, 20574.

37. Abbott, A.P., R.C. Harris, K.S. Ryder, C. D'Agostino, L.F. Gladden, and M.D. Mantle, Green Chemistry, 2011, 13, 82.

38. Shahbaz, K., S. Baroutian, F. Mjalli, M. Hashim, and I. AINashef, Thermochimica Acta, 2012, 527, 59.

39. Abbott, A.P., G. Capper, D.L. Davies, R.K. Rasheed, and V. Tambyrajah, Chemical Communications, 2003, 70.

40. Abbott, A.P., G. Capper, and S. Gray, ChemPhysChem, 2006, 7, 803.

41. Abbott, A.P., J.C. Barron, K.S. Ryder, and D. Wilson, Chemistry-A European Journal, 2007, 13, 6495.

42. Kareem, M.A., F.S. Mjalli, M.A. Hashim, and I.M. AINashef, Journal of Chemical \& Engineering Data, 2010, 55, 4632.

43. Shahbaz, K., F. Mjalli, M. Hashim, and I. AINashef, Energy \& Fuels, 2011, 25, 2671.

44. Williams, J.D., W. Svrcek, and W. Monnery, Developments in Chemical Engineering and Mineral Processing, 2003, 11, 267.

45. Mjalli, F.S., J. Naser, B. Jibril, V. Alizadeh, and Z. Gano, Journal of Chemical \& Engineering Data, 2014, 59, 2242.

46. Abo-Hamad, A., M. Hayyan, M.A. AlSaadi, and M.A. Hashim, Chemical Engineering Journal, 2015, 273, 551.

47. Abbott, A.P., G. Capper, D.L. Davies, and R. Rasheed, Inorganic chemistry, 2004, 43, 3447.

48. AlOmar, M.K., M. Hayyan, M.A. Alsaadi, S. Akib, A. Hayyan, and M.A. Hashim, Journal of Molecular Liquids, 2016, 215, 98.

49. Bahadori, L., M.H. Chakrabarti, F.S. Mjalli, I.M. AINashef, N.S.A. Manan, and M.A. Hashim, Electrochimica Acta, 2013, 113, 205.

50. Abbott, A.P., R.C. Harris, and K.S. Ryder, The Journal of Physical Chemistry $B, 2007,111,4910$.

51. Giap, S.G.E., Journal of Physical Science, 2010, 21, 29.

52. Vila, J., P. Gines, J. Pico, C. Franjo, E. Jimenez, L. Varela, and O. Cabeza, Fluid Phase Equilibria, 2006, 242, 141. 
53. Gan, Q., D. Rooney, M. Xue, G. Thompson, and Y. Zou, Journal of Membrane Science, 2006, 280, 948.

54. Zhou, Z.B., H. Matsumoto, and K. Tatsumi, Chemistry-A European Journal, 2004, 10, 6581.

55. Nishida, T., Y. Tashiro, and M. Yamamoto, Journal of Fluorine Chemistry, 2003, 120, 135.

56. Huddleston, J.G., A.E. Visser, W.M. Reichert, H.D. Willauer, G.A. Broker, and R.D. Rogers, Green chemistry, 2001, 3, 156.

57. Zhao, D., Z. Fei, C.A. Ohlin, G. Laurenczy, and P.J. Dyson, Chemical communications, 2004, 2500.

58. Berthod, A., M. Ruiz-Angel, and S. Carda-Broch, Journal of Chromatography $A, 2008,1184,6$.

59. Greaves, T.L., A. Weerawardena, C. Fong, I. Krodkiewska, and C.J. Drummond, The Journal of Physical Chemistry B, 2006, 110, 22479.

60. Greaves T.L., Weerawardena A., Fong C., Drummond C.J., Langmuir, 2007, 23, 402.

61. Kulkarni, P.S., L.C. Branco, J.G. Crespo, M.C. Nunes, A. Raymundo, and C.A. Afonso, Chemistry-A European Journal, 2007, 13, 8478.

62. Yoshida, Y., K. Muroi, A. Otsuka, G. Saito, M. Takahashi, and T. Yoko, Inorganic chemistry, 2004, 43, 1458.

63. Zhou, Z.B., H. Matsumoto, and K. Tatsumi, ChemPhysChem, 2005, 6, 1324.

64. Mateus, N.M., L.C. Branco, N.M. Lourenço, and C.A. Afonso, Green Chemistry, 2003, 5, 347.

65. Branco, L.C., J.N. Rosa, J.J. Moura Ramos, and C.A. Afonso, Chemistry-A European Journal, 2002, 8, 3671.

66. Gupta, O.D., B. Twamley, and M.S. Jean'ne, Tetrahedron letters, 2004, 45, 1733.

67. Zhou, Z.-B., H. Matsumoto, and K. Tatsumi, Chemistry Letters, 2004, 33, 886. 